\title{
ANALISIS PENINGKATAN KUALITAS PELAYANAN BONGKAR MUAT BARANG DI PELABUHAN PROBOLINGGO (Studi Kasus PT Delta Arta Bahari Nusantara Cabang Probolinggo)
}

\author{
Ardhian Trilaksono $^{1 *}$ Indung Sudarso ${ }^{2}$ \\ ${ }^{1,2}$ Magister Teknik Industri, Fakultas Teknologi Industri, Institut Teknologi Adhi Tama Surabaya \\ Jl. Arief Rachman Hakim 100 Surabaya 60117 \\ *email: ardhiantrilaksono94@gmail.com
}

\begin{abstract}
PT Delta Arta Bahari Nusantara is a regional-owned company owned by the East Java region as a loading and unloading operator for the Probolinggo port trying to improve port operation services, one of the efforts that has been made is building port facilities. There is an increase in loading and unloading activities of superior commodities, it is necessary to increase the quality. Efforts to maintain service quality of a company must analyze and serve data and information accordingly from data and measurements, in this case, product suitability and customer satisfaction levels. The purpose of this research is to measure the service quality of PT Delta Arta Bahari Nusantara uses 5 service quality dimensions, the measurement results (gap) between customer perceptions and expectations are evaluated by the Quality Function Deployment (QFD method. Furthermore, based on the policy (gap) and QFD, strategies are formulated that must be carried out. The results of the analysis showed that all dimensions resulted in a satisfaction level of "less satisfied" (Gap value between -1.5 to -2.25) which means that in all dimensions of satisfaction, customer service ratings provided by PT Delta Arta Bahari Nusantara is not satisfied with meeting expectations. There are 5 indicators that require immediate improvement. Indicators that require the main priority for improvement are the condition and capacity of the dumping yard as well as the facilities and infrastructure, the layout of the stacking field facilities. Recommendations that can be given by the management are evaluating the maximum capacity with the number of storage for goods to determine the addition of the storage area, making improvements to the layout of the facilities and completing if there are lack of public facilities.
\end{abstract}

Keywords: Quality, Servqual, QFD

\section{Pendahuluan}

Moda transportasi laut merupakan salah satu sarana transportasi yang sangat strategis. Keberadaannya pelabuhan sangat dibutuhkan dalam sistem pengiriman barang untuk memenuhi kebutuhan akan barang dari satu negara ke negara lain dengan kapasitas angkut yang besar. Pelabuhan merupakan salah satu sarana moda transportasi laut yang berfungsi sebagai pusat kegiatan bongkar muat barang serta orang yang datang dari dalam dan luar negeri, dilengkapi dengan fasilitas bongkar muat dengan mengutamakan keselamatan para pengguna jasa transportasi (Dephub 2020). Pelabuhan sebagai penyedia jasa pelayanan jasa kepelabuhan diharapkan mampu memberikan pelayanan yang prima, sehingga pelanggan tidak dirugikan dengan peningkatan biaya akibat pelayanan yang tidak optimal (Saffan, Syairudin, and Achmadi 2018). Pelabuhan harus meningkatkan fungsinya dan kualitas pelayanan melalui fasilitas dan teknologi yang digunakan untuk memberikan produktivitas dan cepatnya pergerakan barang dalam sistem transportasi laut (Elvan and Hindiantoro 2019). Peranan penting di pegang pelabuhan yang berfungsi sebagai moda transportasi laut harus dapat mengikuti kebutuhan dan kualitas layanan bagi masyarakat (Malisan 2017).

PT Delta Arta Bahari Nusantara merupakan badan usaha milik daerah Jawa Timur sebagai operator bongkar muat pelabuhan probolinggo berusaha meningkatkan pelayanan operasi pelabuhan, salah satu upaya yang telah dilakukan adalah membangun sarana fasilitas Pelabuhan antara lain lapangan penumpukan (stock pile), causeway, trestle dan dermaga tahap - I kedalaman $6 \mathrm{~m}$ LWS (Low Water Spring), dermaga tahap - II dengan kedalaman - $11 \mathrm{~m}$ LWS. Dengan adanya pengembangan pelabuhan Probolinggo dimungkinkan akan bertambah kunjungan kapal dan bongkar muat barang serta 
kegiatan lainnya. Berdasarkan data bongkar muat di terminal baru pelabuhan Probolinggo periode tahun 2016 sampai Juni 2020 adanya peningkatan dalam aktivitas bongkar muat komoditi unggulan.

Tabel 1. Bongkat Muat Komoditi Unggulan Pelabuhan Probolinggo

\begin{tabular}{llrr}
\hline \multirow{4}{*}{ Tahun } & \multicolumn{2}{c}{ Komoditi (Ton/M3) } & \\
& $\begin{array}{l}\text { Dalam } \\
\text { Negeri }\end{array}$ & \multicolumn{1}{c}{ Luar Negeri } & Jumlah \\
2016 & 432.578 & - & 432.578 \\
2017 & 749.633 & 78.961 & 828.594 \\
2018 & 795.052 & 171.911 & 966.963 \\
2019 & 849.836 & 316.589 & 1.166 .425 \\
2020 & 841.877 & 179.951 & 1.021 .828 \\
\hline
\end{tabular}

Jumlah bongkar muat komoditi unggulan di pelabuhan probolinggo tahun 2016 untuk komoditi barang dalam negeri sebesar 432.578 ton $/ \mathrm{m}^{3}$. Tahun 2017 komoditi dalam negeri $749.633 \mathrm{ton} / \mathrm{m}^{3}$ dan komoditi luar negeri 78.961 ton $/ \mathrm{m}^{3}$. Tahun 2018 bongkar muat komoditi dalam negeri bergerak naik menjadi 795.052 ton $/ \mathrm{m}^{3}$ dan komoditi luar negeri sebesar 171.911 ton $/ \mathrm{m}^{3}$. Tahun 2019 bongkar muat komoditi dalam negeri sebesar $849.836 \mathrm{ton} / \mathrm{m}^{3}$ dengan jumlah bongkar muat komoditi luar negeri sebesar 316.589 ton $/ \mathrm{m}^{3}$. Laporan berjalan tahun 2020, sampai bulan Juni jumlah bongkar muat untuk komoditi dalam negeri sebesar 841.877 ton $/ \mathrm{m}^{3}$ dan untuk komoditi luar negeri sebesar $179.951 \mathrm{ton} / \mathrm{m}^{3}$. Mengantisipasi perkembangan ekonomi nasional dan internasional yang tidak menentu serta persaingan yang ketat diantara pelaku bisnis bongkar muat pelabuhan, maka PT Delta Arta Bahari Nusantara merupakan badan usaha milik daerah Jawa Timur sebagai operator bongkar muat pelabuhan harus menjaga kualitas pelayanan dan melakukan pengelolaan dengan baik.

Berdasarkan hal tersebut peningkatkan kepuasan pengguna jasa terhadap layanan PT Delta Arta Bahari Nusantara dari semua sisi baik fasilitas dan sarana, SDM serta operasional sangat diperlukan untuk membuat kepercayaan pelanggan terjaga dan berdampak pada semakin besarnya kemajuan PT Delta Arta Bahari Nusantara. Berdasarkan pemaparan di atas, maka dilakukan penelitian ini untuk menganalisa persepsi dan harapan pelanggan dengan metode Service Quality (SERVQUAL) untuk mengukur kualitas layanan PT Delta Arta Bahari Nusantara. Metode SERVQUAL ini digunakan untuk mengklasifikasikan layanan perusahaan berdasarkan lima dimensi kualitas layanan (tangibles, realibility, responsiveness, assurance, dan emphaty). Hasil pengukuran kesenjangan (gap) antara persepsi dan harapan pelanggan dievaluasi dengan metode Quality Function Deployment (QFD). Selanjutnya berdasarkan pengukuran kesenjangan (gap) dan QFD, dilakukan penyusunan strategi-strategi yang sebaiknya dilakukan oleh PT Delta Arta Bahari Nusantara untuk meningkatkan kualitas pelayanan. Tujuan penelitian adalah Mengukur besarnya kesenjangan antara persepsi dan harapan kualitas layanan yang diterima dengan mengidentifikasi faktor prioritas pelayanan dan menyusun langkah-langkah perbaikan kualitas layanan bongkar muat pelabuhan.

\section{Landasan Teori}

Pelabuhan pada umumnya terletak di perbatasan antara laut dengan daratan, atau terletak di sungai atau danau (Lasse 2014). Pelabuhan merupakan tempat untuk transportasi laut yang berfungsi sebagai penghubung 2 moda angkutan atau lebih yang dibutuhkan banyak pihak (Gultom 2017).

Kualitas adalah keseluruhan fitur dan karakteristik produk atau layanan yang menghasilkan kemampuannya untuk memenuhi kebutuhan yang dinyatakan atau tersirat (Kotler and Keller 2012). Kualitas pelayanan diukur menggunakan dimensi dan atribut untuk memperoleh nilai kesenjangan berdasarkan hasil selisih dari nilai persepsi pelanggan terhadap pelayanan yang diberikan dengan keinginan yang akan diperoleh dari suatu pelayanan (Ulpa, Teguh, and Pratama 2021). Pengukuran kualitas jasa dalam metode SERVQUAL menggunakan lima dimensi untuk mengukur tingkat keinginan dan persepsi pelanggan, serta gap diantara keduanya dalam dimensi-dimensi kualitas jasa (Asnawi 2017). Kualitas pelayanan harus di tingkatkan dalam menghadapi persaingan pasar global pelabuhan untuk memenuhi kepuasan pengguna jasa pelabuhan (Subhan 2018). Metode Importance Performance Analysis (IPA) digunakan untuk mengetahui tingkat kinerja setiap indikator kualitas pelayanan sesuai persepsi dan harapan yang digambar dalan diagram kartesius (Raekhan, Djakfar, and Pujiraharjo 2017). Importance Performances Analysis (IPA) adalah tools untuk membandingkan sampai sejauh mana tingkat kinerja pelayanan dengan tingkat kepuasan yang dirasakan pelanggan (Saputri, Bambang, and Pramitasari 2014).

Qualitiy Function Deployment adalah metode yang digunakan untuk menyusun dan merancang yang bersumber dari hasil keinginan kebutuhan pelanggan (Wijaya 2018). Metode Qualitiy Function Deployment (QFD) mempunyai karakteristik yang dapat menerjemahkan sebuah keinginan dan kebutuhan pelanggan untuk di wujudkan oleh organisasi dengan tujuan memenuhi kualitas yang sesuai dengan harapan pelanggan (Prasmoro, Chotimah, and Siregar 2020). House of Quality merupakan tools untuk 
mengambarkan kebutuhan pelanggan yang terdiri dari kebutuhan pelanggan (Whats) dan Technical Description (Hows) yang memetakan hubungan masing-masing dimensi kualitas pelayanan (Saputri et al. 2014).

\section{Metode Penelitian}

Pengambilan sampel penelitian menggunakan metode sampling random yang dilakukan secara acak menggunakan tingkat kepercayaan $95 \%$ dan tingkat kesalahan sebesar 5\% dengan jumlah sampel adalah 50 responden dengan populasi 58 pelanggan pengguna jasa bongkar muat pelabuhan.

Analisis awal dalam penelitian ini mengukur tingkat kesenjangan (gap) antara persepsi dan harapan terhadap layanan yang diberikan PT Delta Arta Bahari Nusantara. Metode analisa gap digunakan untuk menganalisis dan menghitung nilai persepsi dan harapan.

Selanjutnya langkah kedua yaitu menyusun diagram kartesius untuk memetakan dan mengetahui posisi masing-masing indikator pelayanan kedalam empat kuadran IPA sehingga dapat membantu memberikan prioritas perbaikan yang akan dilakukan oleh manajemen dalam mengambil keputusan dan kebijakan strategis.

Prioritas perbaikan juga menggunakan voice of customer yang merupakan bagian dari metode Quality Function Deployment (QFD). Metode QFD untuk perencanaan dan pengembangan pelayanan sesuai dengan keinginan pelanggan dan kemampuan manajemen dalam meningkatkan kualitas pelayanan.

\section{Hasil Dan Pembahasan}

Penyusunan indikator menggunakan lima dimensi kualitas pelayanan pada metode Servqual. Hasil analisis gap untuk masing-masing dimensi kualitas disajikan pada tabel berikut.

Tabel 2. Kepuasan Pelanggan Bongkar Muat Pelabuhan Berdasarkan Dimensi Kualitas

\begin{tabular}{lcccl}
\hline \multicolumn{1}{c}{ Dimensi } & Harapan & Realita & Gap & $\begin{array}{l}\text { Tingkat } \\
\text { Kepuasan }\end{array}$ \\
$\begin{array}{l}\text { Penampilan Fisik } \\
\text { (Tangible) }\end{array}$ & 3,88 & 3,68 & $-0,200$ & $\begin{array}{l}\text { Kurang } \\
\text { puas }\end{array}$ \\
$\begin{array}{l}\text { Kehandalan } \\
\text { (Reliability) }\end{array}$ & 3,99 & 3,60 & $-0,390$ & Tidak Puas \\
$\begin{array}{l}\text { Ketanggapan } \\
\text { (Responsiveness) }\end{array}$ & 3,93 & 3,84 & $-0,084$ & Puas \\
$\begin{array}{l}\text { Kepastian } \\
\text { (Assurance) }\end{array}$ & 3,9 & 3,6 & $-0,300$ & Tidak Puas \\
$\begin{array}{l}\text { Empati } \\
\text { (Empathy) }\end{array}$ & 3,99 & 3,73 & $-0,260$ & Tidak Puas \\
\hline Rata-rata & 3,94 & 3,69 & $-0,247$ & $\begin{array}{l}\text { Kurang } \\
\text { puas }\end{array}$ \\
\hline
\end{tabular}

Hasil yang disajikan pada tabel diatas, seluruh dimensi menunjukkan nilai gap negatif, sehingga nilai kualitas masing-masing dimensi belum memenuhi ekspektasi pelanggan.

Langkah selanjutnya dilakukan analisa menggunakan IPA. Untuk mengukur kepuasan kedalam 4 kuadran IPA sehingga dapat diketahui indikator mana yang perlu dilakukan perbaikan.

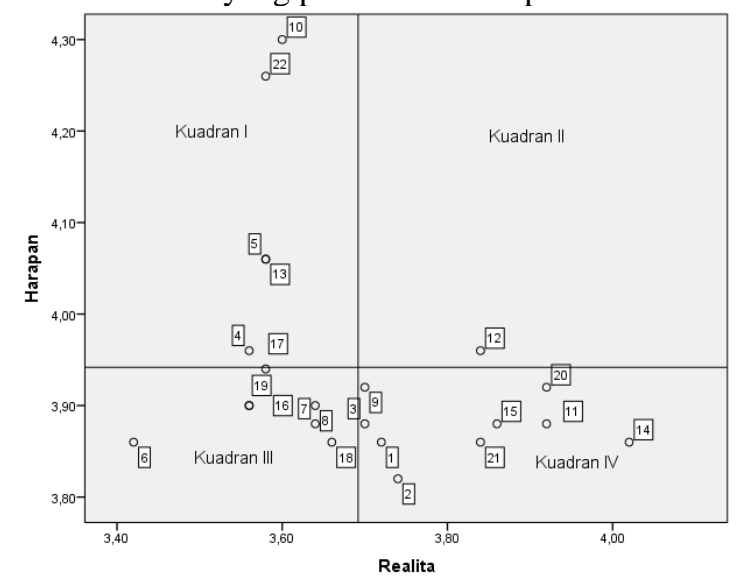

Gambar 1. Diagam Kartesius Kepuasan

Pelanggan PT. Delta Arta Bahari Nusantara Sumber: pengolahan Data

Berdasarkan 4 kuadran pada diagram kartesius diatas, maka dapat diketahui bahwa pada kuadran I terdapat 5 indikator yang artinya layanan tersebut harus segera diperbaiki. Pada Kuadran II terdapat 7 indikator yang harus dipertahakan. 9 indikator masuk pada Kuadran III dan 9 indikator masuk ke dalam Kuadran IV.

Setelah diketahui indikator yang masuk dalam kuadran I sebagai prioritas perbaikan maka selanjutnya dilakukan analisis menggunakan QFD dengan pedekatan voice of customer (VOC) yang digunakan untuk pengembangan dan perbaikan kualitas pelayanan bongkar muat serta inovasi pelayanan.

Tabel 3. Tabel Matriks Kebutuhan Konsumen (Whats)

\begin{tabular}{|c|c|}
\hline \multirow{5}{*}{ 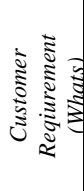 } & Jarak dermaga dengan lapangan penumpukan \\
\hline & Keadaan dan kapasitas lapangan penumpukan \\
\hline & Penerangan di pelabuhan (malam hari) \\
\hline & Keramahan pelayanan petugas pelabuhan \\
\hline & $\begin{array}{l}\text { Koordinasi yang baik antara petugas dengan } \\
\text { customer }\end{array}$ \\
\hline
\end{tabular}

Sementara itu, respon teknik (Hows) merupakan respon atau tindakan yang akan dilakukan oleh pihak manajemen PT Delta Arta Bahari Nusantara terhadap keinginan konsumen.

Tabel 4. Matriks Respon Teknis (Hows)

\begin{tabular}{|l|l|}
\hline \multirow{2}{*}{} & $\begin{array}{l}\text { Melakukan perbaikan tata ruang area penumpukan } \\
\text { sehingga jarak dermaga lebih dekat }\end{array}$ \\
\cline { 2 - 3 } & $\begin{array}{l}\text { Melakukan perbaikan, penataan ulang, dan } \\
\text { penambahan Lapangan Penumpukan sehingga } \\
\text { memadai dan layak }\end{array}$ \\
\cline { 2 - 2 } & $\begin{array}{l}\text { Menambah jumlah lampu penerangan sesuai } \\
\text { dengan jarak dan sudut pandang saat bongkar muat } \\
\text { di dermaga }\end{array}$ \\
\cline { 2 - 2 } & $\begin{array}{l}\text { Melakukan pelatihan kepada petugas secara berkala } \\
\text { setiap bulan }\end{array}$ \\
\cline { 2 - 2 } & $\begin{array}{l}\text { Memperbaiki standart operasional kerja dan } \\
\text { kontroling }\end{array}$ \\
\hline \multirow{2}{*}{} &
\end{tabular}


Setelah diperoleh 5 indikator melalui voice of customer, selanjutnya dilakukan analisa menggunakan QFD sehingga diperoleh 5 indikator kualitas pelayanan yang memerlukan perbaikan, dengan nilai masing-masing indikator ditunjukkan sebagai berikut.

Tabel 5. Nilai Tingkat Kepentingan, Target Value dan Customer Satisfaction

\begin{tabular}{llccr}
\hline $\mathrm{N}$ & \multicolumn{1}{c}{ Pernyatan } & $\begin{array}{c}\text { Tingka } \\
\mathrm{t} \\
\text { Kepent } \\
\text { ingan }\end{array}$ & $\begin{array}{c}\text { Target } \\
\text { Value } \\
\text { (Harapa } \\
\mathrm{n})\end{array}$ & $\begin{array}{c}\text { Customer } \\
\text { Satisfactio } \\
\mathrm{n} \text { (Realita) }\end{array}$ \\
& $\begin{array}{l}\text { Jarak dermaga } \\
\text { dengan lapangan } \\
\text { penumpukan } \\
\text { Keadaan dan } \\
\text { kapasitas lapangan } \\
\text { penumpukan }\end{array}$ & 3,42 & 3,96 & 3,56 \\
& $\begin{array}{l}\text { Penerangan di } \\
\text { pelabuhan (malam } \\
\text { hari) }\end{array}$ & 4,20 & 4,06 & 3,58 \\
& $\begin{array}{l}\text { Keramahan } \\
\text { pelayanan petugas } \\
\text { pelabuhan }\end{array}$ & 3,64 & 4,30 & 3,60 \\
$\begin{array}{l}\text { Koordinasi yang } \\
\text { baik antara petugas } \\
\text { dengan customer }\end{array}$ & 3,66 & 4,06 & 3,58 \\
\hline
\end{tabular}

Sedangkan untuk nilai Importance to Customer, Improvement Ratio, Sales Point dan Absolute Weight disajikan pada tabel berikut.

Tabel 6. Nilai Importance to Customer, Improvement Ratio, Sales Point dan Absolute Weight

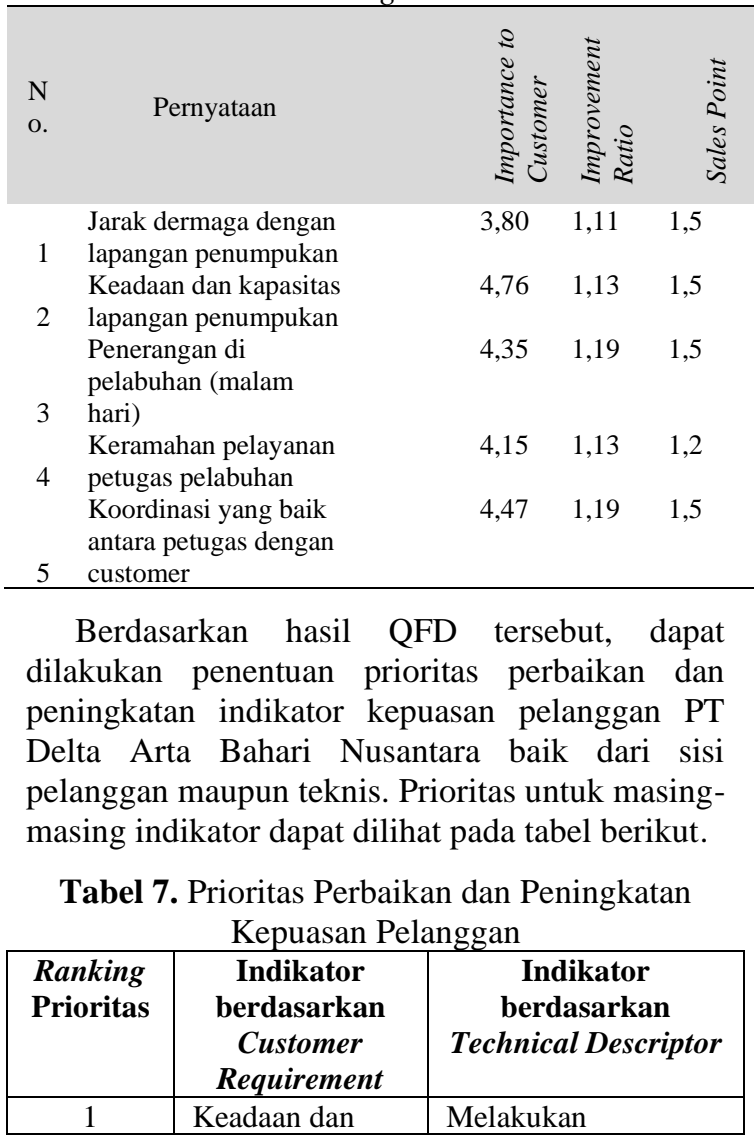

\begin{tabular}{|c|l|l|}
\hline & $\begin{array}{l}\text { kapasitas } \\
\text { lapangan } \\
\text { penumpukan }\end{array}$ & $\begin{array}{l}\text { perbaikan, penataan } \\
\text { ulang, dan } \\
\text { penambahan } \\
\text { Lapangan } \\
\text { Penumpukan } \\
\text { sehingga memadai } \\
\text { dan layak }\end{array}$ \\
\hline 2 & $\begin{array}{l}\text { Koordinasi yang } \\
\text { baik antara } \\
\text { petugas dengan } \\
\text { customer }\end{array}$ & $\begin{array}{l}\text { Memperbaiki standart } \\
\text { operasional kerja dan } \\
\text { kontroling }\end{array}$ \\
\hline 3 & $\begin{array}{l}\text { Penerangan di } \\
\text { pelabuhan } \\
\text { (malam hari) }\end{array}$ & $\begin{array}{l}\text { Menambah jumlah } \\
\text { lampu penerangan } \\
\text { sesuai dengan jarak } \\
\text { dan sudut pandang } \\
\text { saat bongkar muat di } \\
\text { dermaga }\end{array}$ \\
\hline 4 & $\begin{array}{l}\text { Jarak dermaga } \\
\text { dengan lapangan } \\
\text { penumpukan }\end{array}$ & $\begin{array}{l}\text { Melakukan perbaikan } \\
\text { tata ruang area } \\
\text { penumpukan } \\
\text { sehingga jarak } \\
\text { dermaga lebih dekat }\end{array}$ \\
\hline 5 & $\begin{array}{l}\text { Keramahan } \\
\text { pelayanan } \\
\text { petugas } \\
\text { pelabuhan }\end{array}$ & $\begin{array}{l}\text { Melakukan pelatihan } \\
\text { kepada petugas secara } \\
\text { berkala setiap bulan }\end{array}$ \\
\hline
\end{tabular}

Dari 5 indikator tersebut maka diketahui bahwa perbaikan yang dilakukan mengarah pada prioritas utama perbaikan pada keadaan dan kapasitas lapangan penumpukan, sehingga hal ini perlu diprioritaskan dalam meningkatkan kualitas pelayanan bongkar muat pelabuhan. Hasil analisis dari QFD digunakan sebagai rekomendasi perbaikan yang dilakukan oleh manajemen.

Tabel 8. Rekomendasi dan Solusi Perbaikan Kepuasan Pelanggan PT Delta Arta Bahari Nusantara

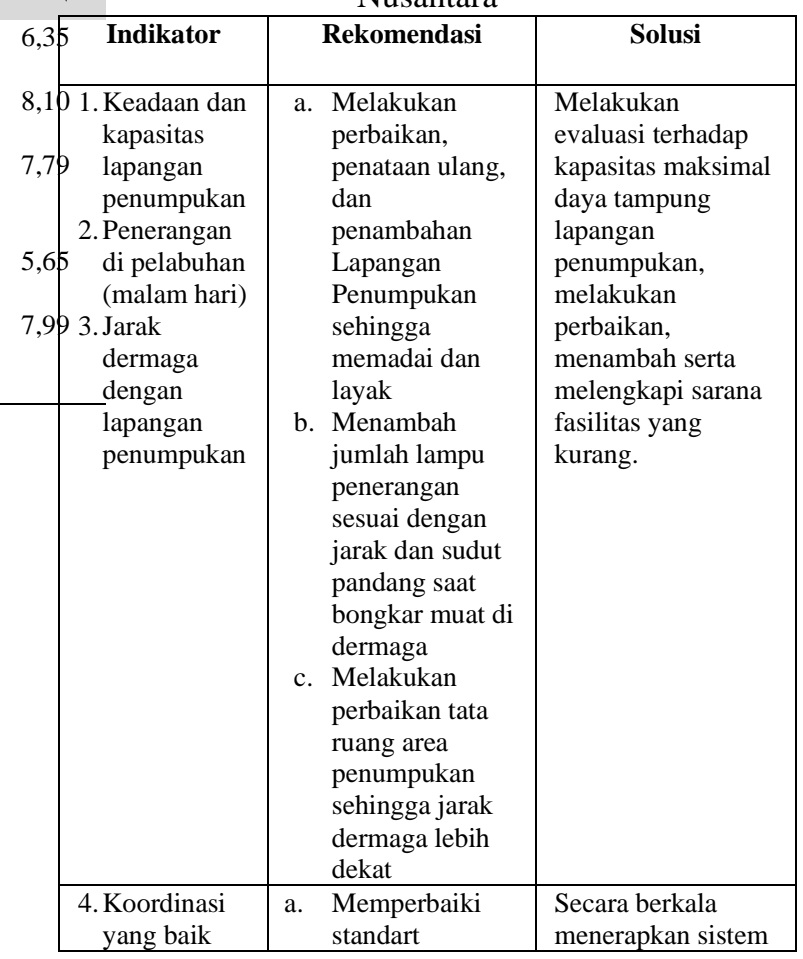




\begin{tabular}{|c|c|c|}
\hline $\begin{array}{l}\text { antara } \\
\text { petugas } \\
\text { dengan } \\
\text { customer } \\
\text { 5. Keramahan } \\
\text { pelayanan } \\
\text { petugas } \\
\text { pelabuhan }\end{array}$ & $\begin{array}{ll} & \text { operasional } \\
& \text { kerja dan } \\
& \text { kontroling } \\
\text { b. } & \text { Melakukan } \\
\text { pelatihan } \\
\text { kepada petugas } \\
\text { secara berkala } \\
\text { setiap bulan }\end{array}$ & $\begin{array}{l}\text { penilaian kinerja } \\
\text { pegawai (seperti } \\
\text { reward dan } \\
\text { punishment), } \\
\text { pembentukan } \\
\text { lingkungan kerja } \\
\text { yang kondusif, dan } \\
\text { pelatihan yang } \\
\text { berkelanjutan untuk } \\
\text { peningkatan } \\
\text { kompetensi dan } \\
\text { profesionalisme }\end{array}$ \\
\hline
\end{tabular}

\section{Kesimpulan}

Berdasarkan hasil analisis dan pembahasan kepuasan pelanggan bongkar muat pelabuhan PT Delta Arta Bahari Nusantara dengan cakupan 5 dimensi kepuasan pelanggan yang digunakan yaitu tangible, reliability, responsiveness, assurance, dan empathy diperoleh bahwa hasil analisis Gap menunjukkan seluruh dimensi menghasilkan tingkat kepuasan "kurang puas" (nilai Gap antara -1,5 sampai dengan -2,25) yang dapat diartikan bahwa pada seluruh dimensi kepuasan, pelanggan menilai pelayanan yang diberikan PT Delta Arta Bahari Nusantara kurang puas memenuhi harapan. Hasil analisis diagram kartesius terdapat 5 indikator yang memerlukan perbaikan segera antara lain Jarak dermaga dengan lapangan penumpukan, Keadaan dan kapasitas lapangan penumpukan, Penerangan di pelabuhan (malam hari), Keramahan pelayanan petugas pelabuhan, Koordinasi yang baik antara petugas dengan customer. Hasil analisa QFD menunjukkan Indikator yang memerlukan prioritas utama adalah indikator keadaan dan kapasitas lapangan penumpukan serta sarana dan prasarana, tata letak fasilitas lapangan penumpukan. Sehingga rekomendasi yang dapat diberikan pihak manajemen yaitu melakukan evaluasi terhadap kapasitas maksimal daya tampung lapangan penumpukan, melakukan perbaikan, menambah serta melengkapi sarana fasilitas yang kurang.

\section{Daftar Referensi}

Asnawi, Anita. 2017. "Servqual Model Terhadap Kepuasan Pelanggan Pada Jasa Bongkar Muat Dan EMKL." Jurnal Ilmiah Administrasi Bisnis Dan Inovasi 1(1):1-13.

Dephub. 2020. "Sejarah Pelabuhan Probolinggo." KSO Probolinggo. Retrieved (http://dephub.go.id/org/ksopprobolinggo/se jarah).

Elvan, Sri Ayu, and Septo Hindiantoro. 2019.

"Upaya Meningkatkan Kepuasan Pengguna Jasa Terhadap Pelayanan Keagenan PT .
Pelayaran Ekanuri Indra Pratama Di Tanjung Priok Jakarta.” Urnal Sains Teknologi Transportasi Maritim I(1):37-45.

Gultom, Elfrida. 2017. "Pelabuhan Indonesia Sebagai Penyumbang Devisa Negara Dalam Perspektif Hukum Bisnis.” Kanun Jurnal Ilmu Hukum 19(3):419-44.

Kotler, Philip, and Kevin Lane Keller. 2012. Manajemen Pemasaran. 12th ed. Jakarta: Erlangga.

Lasse, D. A. 2014. Manajemen Pelabuhan. Jakarta: Raja Grafindo Persada.

Malisan, Johny. 2017. “Analisis Tingkat Pelayanan Terminal Penumpang Pelabuhan Balikpapan.” Jurnal Penelitian Transportasi Laut 19(1):76-87.

Prasmoro, Alloysius Vendhi, Chusnul Chotimah, and Denny Siregar. 2020. "Analisis Perbaikan Kualitas Pelayanan Menggunakan Metode Quality Function Deployment (Studi Kasus Cafe XYZ Rawalumbu)." Journal of Industrial and Engineering System (JIES) 1(2):89-100.

Raekhan, M. Rum, Ludfi Djakfar, and Alwafi Pujiraharjo. 2017. "Evaluasi Kinerja Bongkar Muat Di Pelabuhan Umum Gresik." Jurnal Transportasi 17(2):133-44.

Saffan, Dafazal, Bambang Syairudin, and Fuad Achmadi. 2018. "Analisis Kepuasan Pelayanan Dan Loyalitas Pelanggan Dengan Menggunakan Metode Servqual, IPA, Dan QFD Di Terminal Teluk Lamong." Business and Finance Journal 3(1):1-6.

Saputri, Debby Weviditya, Azis Nur Bambang, and Sulistiyani dyah Pramitasari. 2014. "Analisis Kualitas Pelayanan Pelabuhan Perikanan Pantai (PPP) Morodemak, Kabupaten Demak." Journal of Fisheries Resources Utilization Management and Technology 3(3):65-73.

Subhan, Ali. 2018. "Analisis Dimensi Kualitas Pelayanan Pada Perusahaan Jasa Pelabuhan Curah Pt. Krakatau Bandar Samudera Cilegon Menggunakan Metoda Servqual.” Jurnal Media Teknik Dan Sistem Industri 2(2):20.

Ulpa, Dwiki Yosinta, Rizani Teguh, and Dicky Pratama. 2021. "Analisis Kualitas Pelayanan Aplikasi Lazada Berbasis Mobile 
Dengan Metode Servqual.” JTSI 2(1):3848.

Wijaya, Tony. 2018. Manajemen Kualitas Jasa

Desain Servqual QFD Dan Kano. Edisi

Kedu. jakarta: Indeks Jakarta. 